\title{
DOSSIÊ \\ MANUAIS ESCOLARES: \\ MÚLTIPLAS FACETAS \\ DE UM OBJETO CULTURAL
}

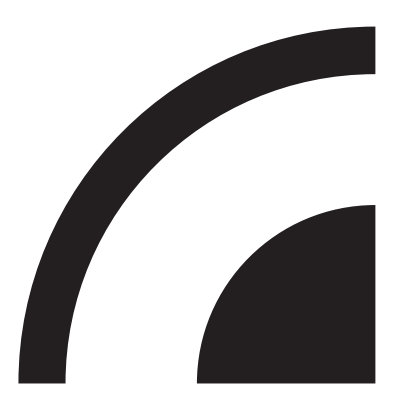

Organização
Heloísa Helena Pimenta Rocha
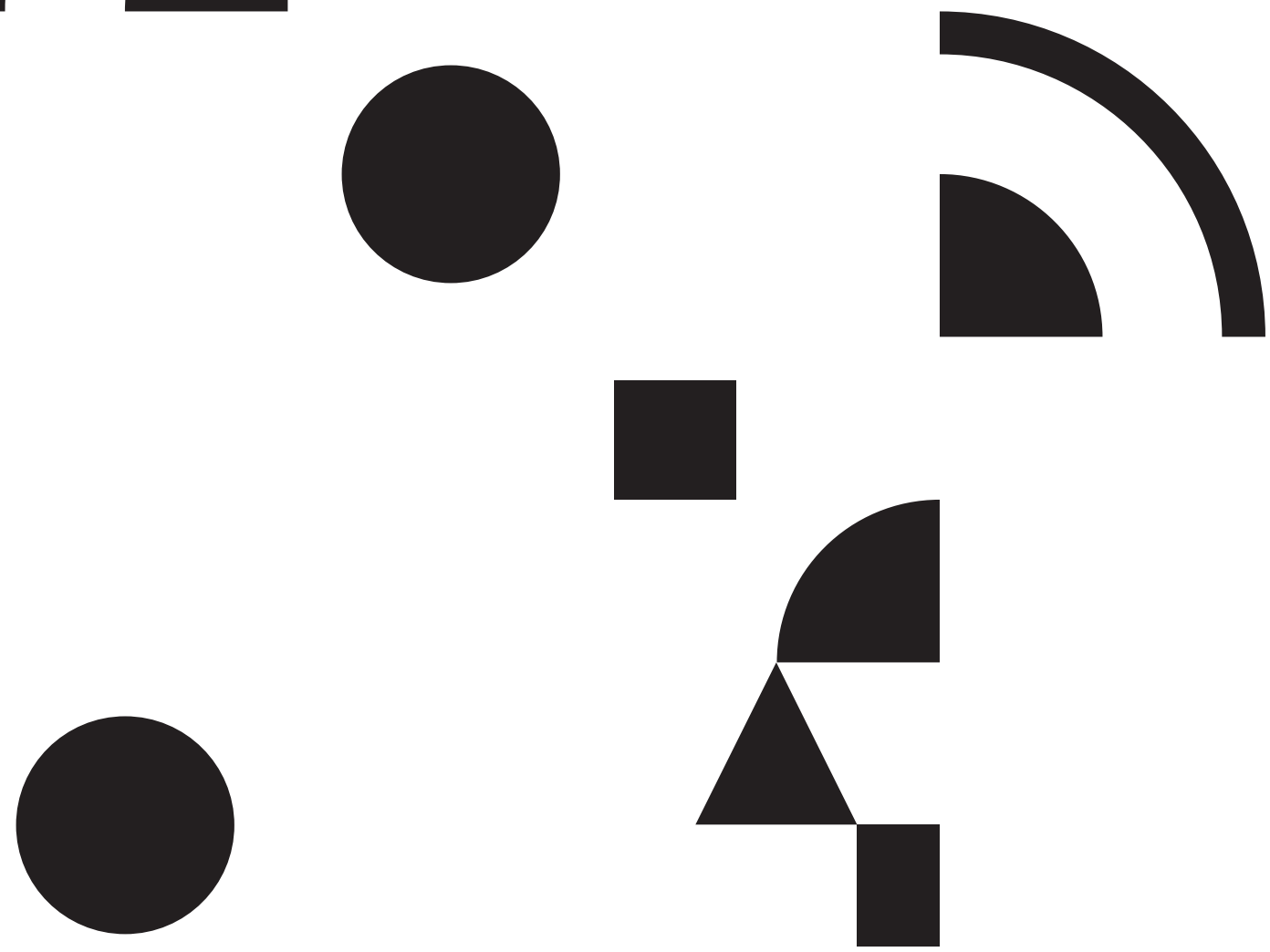


\title{
Apresentação do dossiê Manuais escolares: múltiplas facetas de um objeto cultural
}

\author{
Heloísa Helena Pimenta Rocha*, Miguel Somoza**
}

$\mathrm{D}$ ispositivo fundamental no projeto de difusão da escolarização em massa que acompanhou a constituição dos Estados Nacionais, recurso educativo mais presente e mais cotidianamente utilizado nas salas de aula dos vários cantos do mundo, o livro escolar vem se configurando em objeto de interesse de equipes de pesquisadores de vários países.

Sem desmerecer os trabalhos anteriores realizados por numerosos pesquisadores individuais, o campo de estudos sobre os livros escolares iniciou-se, provavelmente, no âmbito de um dos primeiros programas sistemáticos de pesquisa, coordenado pelo historiador Georg Eckert, no fim da Segunda Guerra Mundial, com o propósito de analisar os conteúdos desses livros, em relação, sobretudo, com as identidades nacionais e o ensino do patriotismo. Sob os auspícios da Unesco, os estudos de Eckert voltaram-se para a análise do papel dos livros escolares na formação das consciências nacionais, com o fim de contribuir para a ampliação da compreensão mútua entre os habitantes dos países que haviam participado daquele conflito. Tal investimento teve como alvo a reconciliação e a paz na Europa e, por extensão, no mundo. Seu legado continua atualmente no Georg-Eckert-Institut für internationale Schulbuchforschung (Instituto Georg Eckert para a pesquisa internacional sobre livros escolares).

Algumas décadas mais tarde, Alain Choppin deu início, na França, ao projeto Emmanuelle, com o intento de inventariar e catalogar os manuais escolares utilizados naquele país, desde a Revolução Francesa até a atualidade. Para isso, criou uma base de dados informatizada e promoveu estudos sobre esse gênero de obras. Os eixos gerais do projeto foram se ampliando, me-
* Professora do Departamento de Educação Conhecimento Linguagem e Arte (Delart) da Faculdade de Educação da Unicamp, Campinas, SP, Brasil. heloisah@unicamp.br

* * Universidad Nacional de Educación a Distancia (UNED), Madri, Espanha. 
diante acordos com outros grupos de investigação e países, dando origem, entre muitos outros, ao projeto Manes, na Espanha; ao projeto Les manuels scolaires québécoises, no Canadá; ao projeto italiano Edisco, que reúne pesquisadores de seis universidades, com o objetivo de estudar a edição de livros escolares, desde 1800 até o presente; ao projeto Livres, sobre os livros escolares brasileiros; e ao Programa HISTELEA, sobre os manuais de leitura e escrita na Argentina. Foram criados, também, grupos internacionais com objetivos similares, como a International Association for Research on Textbooks and Educational Media (IARTEM), e a Internationale Gesellschaft für historische und systematische Schulbuchforschung (Sociedade internacional para a investigação histórica e sistemática de livros escolares) ${ }^{1}$.

Uma das dificuldades iniciais com a qual se defrontaram os pesquisadores foi a ausência de um registro ou censo sistemático das obras escolares utilizadas em cada país. Para tanto, vários dos projetos citados tiveram, como um de seus primeiros objetivos, a realização

1. Para maiores informações sobre os projetos citados, consultar: Georg-Eckert-Institut: http://www.gei.de/; Emmanuelle: http://www. inrp.fr/emma/web/index.php; Manes: http://www.uned.es/manesvirtual/ portalmanes.html; Universidad Laval: http://www.bibl.ulaval.ca/ress/ manscol/; Livres: http://paje.fe.usp.br/estrutura/livres/index.htm; Edisco: http://www.reseducationis.it/edisco/default.aspx; IARTEM: http://www.iartem.no/index.htm; Internationale Gesellschaft... http:// www.schulbuch-gesellschaft.de/. desse inventário e a catalogação das obras destinadas ao uso escolar. Tal ausência não era, evidentemente, fruto do acaso, mas resultava de uma concepção, predominante durante muito tempo, de que as obras escolares e a literatura infantil em geral eram produtos de escasso valor cultural. Como fruto dessa concepção, seus títulos não compunham o patrimônio bibliográfico de prestígio, nem tampouco os poderes públicos se preocupavam com o seu registro ou com a sua conservação.

A realização desses censos trouxe como resultado a criação de bases de dados nacionais de manuais e livros escolares, disponibilizadas posteriormente na internet, com acesso livre, tanto para os pesquisadores como para o público em geral, as quais se constituem, atualmente, em um instrumento fundamental para o desenvolvimento de pesquisas que tomam esses livros como objetos ou fontes.

A base de dados Emmanuelle, por exemplo, registra neste momento mais de 27.000 títulos, correspondentes a aproximadamente 70.000 diferentes edições de manuais franceses. A base Manscol, da Universidade de Laval, dispõe de 26.000 referências de livros escolares produzidos ou utilizados no Quebec, e a base Diaspora des manuels scolaires, da mesma universidade, con- 
ta com mais de 20.000 títulos de livros de instrução escolar dos Irmãos das Escolas Cristãs, congregação fundada por La Salle. A base de dados Manes reúne atualmente mais de 17.000 registros de manuais escolares espanhóis, 7.800 de Portugal, 3.800 da Bélgica e 3.300 de países da América Latina. A base Edisco contempla mais de 20.000 referências de livros italianos, enquanto o Livres reúne mais de 10.000 títulos de livros escolares brasileiros.

Esta significativa quantidade de informação sistematizada põe em relevo o árduo trabalho realizado na última década e aponta para novas e promissoras possibilidades de investigação internacional comparada. Com o propósito de facilitar este tipo de estudos, foi criado também um "metabuscador", recurso de informática que torna possível, até o momento, realizar buscas simultâneas nas bases Emmanuelle, Edisco e Manes, com a perspectiva de ampliação futura às demais bases informatizadas sobre livros escolares ${ }^{2}$.

Cabe assinalar que a pesquisa sobre livros escolares esteve, em suas origens, centrada nos conteúdos das disciplinas humanísticas e das ciências sociais, com base na crença de que tais conteúdos haviam desempenhado um importante papel na configuração das identidades nacionais, sendo utilizados para a transmissão de ideologias dogmáticas e autoritárias. Segundo essa concepção, essas obras teriam se configurado, nesse sentido, em veículo de discriminação social, cultural e de gênero, quer de forma explícita ou implícita.

Com o passar dos anos e a renovação de metodologias e perspectivas teóricas, as investigações foram paulatinamente abarcando todos os campos das disciplinas escolares, criando possibilidades de análise que não se restringiram à influência destas na formação das consciências individuais ou coletivas, mas vêm buscando recobrir a genealogia das próprias disciplinas; os fatores que intervêm na seleção curricular; os autores de livros escolares; a história das editoras especializadas neste tipo de obra, até chegar, em nossos dias, a uma perspectiva mais geral, que considera tais obras como parte da "cultura escolar", por um lado, e como parte dos "meios massivos" de comunicação e ensino, por outro. ${ }^{3} \mathrm{~A}$ estes enfoques, há que somar também o tratamento do livro de texto em sua materialidade, tanto como objeto que constitui um patrimônio cultural valioso, quanto como objeto

2. 0 endereço desse MultiOpac é: 〈http://www.historyonline.eu/multiopac/s.

3. A este respeito, consultar Meda, J. Mezzi di educazione di massa. Nouve fonti e nouve prospettive di recerca per una "storia materiale della scuola" tra XIX e XX secolo. History of Education \& Children Literature, v. VI, n. 1, p. 253-279, 2011. 
produzido por agentes específicos, com técnicas determinadas, em um contexto econômico, comercial e de organização da produção; e, portanto, social e historicamente condicionado 4 .

A preocupação em relação à metodologia e ao estabelecimento de categorias teóricas precisas de investigação evidencia-se em cada congresso, seminário ou encontro de profissionais deste campo. Há que reconhecer, no entanto, que os estudos sobre as disciplinas humanísticas e sociais continuam predominando sobre os que se voltam para disciplinas mais relacionadas com as ciências experimentais ou as matemáticas. Na mesma medida, a análise do conteúdo textual continua prevalecendo sobre a análise iconográfica, sendo ainda escassos os estudos que abordam ambas as perspectivas de maneira integrada e sistemática. Cabe destacar também que, ao privilegiar a análise de conteúdos, a maioria das investigações permanece centrada no momento da emissão da mensagem ou do discurso presente nos livros, sem avançar sobre o momento da recepção. Assim, permancem na penumbra os processos de deco-

4. Nas listas bibliográficas do Centro Manes, que reúnem as publicações sobremanuaisescolaresdosúltimosanos, pode-seobservar, pelasimples leitura dos títulos, 0 amplo e crescente leque de temas abordados e a variedade de perspectivas e metodologias utilizadas nas investigações. Cf. 〈http://www.uned.es/manesvirtual/ProyectoManes/Bibliografia.htm〉. dificação, interpretação, contestação e apropriação que os alunos realizam, assim como as ações de mediação e transformação dos conteúdos originais que os educadores e as próprias instituições escolares produzem, seja de maneira intencional ou contingente.

Certamente, não é casual que estes últimos aspectos tenham recebido menos atenção: a complexidade dos processos envolvidos torna conceitualmente mais difícil este tipo de investigação, ao mesmo tempo que a metodologia e os instrumentos de coleta e análise da informação exigem elevados custos, procedimentos cuidadosos e grupos de investigação maduros e consolidados. Mostra-se extremamente difícil saber o que e quanto os alunos se lembram ou se esquecem de seus livros escolares e o grau em que essas leituras podem ter participado da conformação de suas subjetividades. Entre outras razões, isso se deve ao fato de que há sempre uma distância entre o vivido e o lembrado, na medida em que cada ato de reminiscência altera as lembranças; além do que, o passar do tempo e as experiências transformam as conexões neurais e adequam as experiências às necessidades ou conveniências do tempo presente, em sua dimensão social ou individual.

Do ponto de vista da produção, cabe assinalar que os livros escolares estão 
sujeitos a constantes transformações, alternando-se períodos de mudanças lentas e graduais com momentos de transformações mais intensas e rápidas. Além disso, sofrem a repercussão dos movimentos de reforma pedagógica e das novas metodologias que acompanham tais movimentos, sendo também influenciados pelas transformações técnicas que afetam a indústria editorial e pelas mudanças políticas, econômicas e culturais de alcance nacional e internacional. A revolução nos meios de comunicação, em curso nos últimos anos, e, em particular, as tecnologias digitais e 0 advento da rede mundial de computadores já estão exercendo - e, seguramente, exercerão de modo ainda mais contundente, em um futuro muito próximo - uma grande pressão sobre o formato e a produção dos livros escolares, assim como sobre as maneiras de utilizá-los nas escolas.

É fácil comprovar como seu desenho gráfico vem passando, nos últimos anos, do predomínio do texto para o das imagens; da cor única ou do bicolor ao multicolorido; do papel de baixa qualidade ao de altíssima qualidade. Quanto à produção editorial, os livros escolares vêm deixando de ser "obras de autor" para tornar-se obras de uma "equipe editorial”, muitas vezes anônima ou quase; ao mesmo tempo, vêm deixando de ser produzidos por pequenas empresas especializadas, para converter-se em alvo dos interesses de grandes grupos econômicos editoriais e/ou de multimídia. Nesse sentido, seu alcance ou zona de influência vem se deslocando, ultrapassando o âmbito regional ou nacional, por meio de uma distribuição e competição empresarial em escala internacional. Da organização linear, sequencial e contínua do texto, passa-se à fragmentação e à ordem não sequencial, pela utilização de múltiplos níveis de texto (principais, secundários, descritivos, explicativos, reprodução de fontes primárias, etc.) e variados recursos gráficos, como: mapas geográficos e temáticos, tabelas, quadros estatísticos, sinopses, esquemas. 0 foco de atenção do leitor-aluno, antes centrado em um objeto que o capturava, amplia-se, dando lugar a uma variedade de elementos que o saturam. Os processos de percepção e decifração da comunicação passam da unicidade diacrônica à multiplicidade de tipologias e códigos sincrônicos.

A essas mudanças no modelo impresso, há que somar o aparecimento do manual escolar digital. Em suas origens, os recursos didáticos digitais complementavam os conteúdos impressos, ampliando a informação, por meio da disponibilização de mais imagens, vídeos, mapas, textos, os quais pode- 
riam ser acessados no site da editora. Porém, rapidamente, os manuais escolares digitais vêm adquirindo feição própria. A crescente facilidade de acesso às conexões de alta velocidade e aos próprios computadores, reforçada, em muitos países, por políticas públicas de doação gratuita de computadores portáteis aos alunos e de instalação de equipamentos de informática nas escolas, vai configurando um novo cenário de comunicação e aprendizagem. É legítimo supor que, dentro de não muito tempo, os livros escolares impressos venham a ser um complemento textual dos manuais digitais, o que demandará procedimentos pedagógicos que, nos dias de hoje, são ainda, em boa medida, experimentais e provisórios.

Passada já a primeira fascinação em relação às supostas infinitas possibilidades da tecnologia, alguns autores, transformados agora em críticos pessimistas, alertam para o fato de que a lei-

5. Ver, por exemplo, Carr, N. ¿Qué está haciendo Internet con nuestras mentes? Superficiales. Madrid: Taurus, 2011. Mario Vargas Llosa poderia ser considerado também un exponente ilustre dessa tendência. Pouco depois de receber o prêmio Nobel de Literatura, declarou que "el Internet ha acabado con la gramática, ha liquidado la gramática. De modo que se vive una especie de barbarie sintáctica". Sobre os jovens que abreviam as palavras e não respeitam as regras gramaticais, afirmou: "Si escribes así, es que hablas así: si hablas así, es que piensas así; y si piensas así, piensas como un mono". Ver: 〈http://elcomercio.pe/tecnologia/749462/ noticia-vargas-llosa-jovenes-que-chatean-piensancomo-mono>. Em outro artigo, o próprio Vargas Llosa comenta e assume a tese de Nicholas Carr, “Más información, menos conocimiento", El País, 02/08/2011. Disponível em: 〈http://www.elpais.com/articulo/opinion/informacion/ conocimiento/elpepiopi/20110731elpepiopi_11/Tes〉. tura em telas pode gerar uma inevitável perda da capacidade de leitura e escrita atenta e concentrada. Dessa maneira, novas gerações de leitores-navegadores superficiais, que somente poderiam lidar com textos breves, durante um curto período de tempo, estariam perdendo os recursos intelectuais associados às "dinâmicas psíquicas" características da cultura escrita: a lógica formal e o pensamento analítico 5 .

A relação entre a tecnologia e as mudanças sociais é, obviamente, complexa, cheia de matizes contraditórios e contingências fortuitas. No entanto, distintamente dos autores vinculados a essa corrente que postula o "determinismo tecnológico" nos meios de comunicação, é legítimo afirmar que não é a tecnologia que determina os rumos dos processos sociais a longo prazo, mas a própria tecnologia é um artefato cultural, sujeito a condicionantes sociais, econômicos e políticos. Nesse sentido, e com todas as precauções e limitações que a questão impõe, caberia indagar se e até que ponto a internet estaria fatalmente produzindo gerações de leitores limitados em suas capacidades cognitivas; ou se é possível pensar que, ao contrário, sua potencialidade contribuiria para tornar virtualmente possível a existência de uma sociedade leitora mundial, que constituiria o ponto mais alto da cultura 
baseada na alfabetização. E mais ainda: aos que prognosticam a perda de capacidades intelectuais, poder-se-ia indagar se uma tecnologia de comunicação verbal, textual e icônica complexa, como é a internet, não demandaria dos leitores, por si mesma, capacidades e competências intelectuais maiores, e não menores, do que as que demanda a escrita em papel.

Uma questão distinta é que a cultura contemporânea, caracterizada pelo movimento, pela velocidade, pela vertigem e pelo ruído; dominada pelas regras econômicas da rápida circulação e da acumulação de capital, está presidida pela aceleração do tempo social, de modo que a "falta de tempo" se configura na manifestação vital mais expressiva do “mal-estar da cultura”. Paradoxalmente, quanto mais produtivo se torna o trabaIho humano, menos tempo livre temos para desfrutar dos bens disponíveis. À medida que viajamos, nos comunicamos e produzimos em maior velocidade; as exigências sociais, econômicas e políticas de chegar a maior distância, de acessar mais informação e de conseguir maior produtividade são superiores aos resultados que podem ser alcançados pela tecnologia, gerando uma conduta social obsessiva e ansiosa, que vem penetrando e configurando as subjetividades individuais. É possível pensar, nesse sentido, que este seria um fator muito mais relevante, a ser considerado na análise do fenômeno da "leitura superficial”, do que as supostas características intrínsecas do suporte digital ${ }^{6}$.

Não há motivos para pensar que os livros escolares (obras que, por meio de textos, ilustrações ou sons, desenvolvem total ou parcialmente o currículo de um período letivo, recebam este ou outro nome) desaparecerão das escolas em um futuro próximo. Porém, o fundamental, cremos, é que a escola, como instituição, sob uma forma ou outra, tem muito que fazer na era da internet. As tecnologias eletrônicas devem integrar os processos de ensino e aprendizagem, porque a escola continua tendo um papel essencial na aquisição e na democratização universal dos conhecimentos. 0 cumprimento desses propósitos exige situar a educação e a escola no centro das políticas públicas, porque, definitivamente, o bem-estar do cidadão e a qualidade da democracia são inseparáveis do cuidado e do apreço que concedermos às instituições públicas de educação.

O conjunto de artigos reunidos neste dossiê permite refletir sobre algumas

6. Ver, a esse respeito: Somoza, M. Los saberes letrados en la "sociedad de la información”. Lectura, soportes y ritmos sociales. In: Cucuzza, R.; Spregelburd, P. (dir.). Historia de la lectura en Argentina. Del catecismo colonial a las netbooks estatales. Buenos Aires: Ed. Calderón (no prelo). 
das dimensões hoje tematizadas no estudo dos manuais escolares, possibilitando pensá-los como objetos culturais que encarnam em sua materialidade uma multiplicidade de intenções, objetivos, regulações e, ao mesmo tempo, considerá-los como fontes que informam sobre os valores partilhados em uma determinada época; sobre as representações sociais; e sobre as práticas escolares. Reunindo artigos de alguns dos mais representativos estudiosos do tema, o presente dossiê, cuja organização faz parte da agenda de trabalho conjunto entre a Unicamp, o Centro de Investigación Manes e o Centro Internacional de la Cultura Escolar (Ceince), visa propiciar ao leitor elementos para a reflexão sobre algumas das perspectivas mais inovadoras da produção nessa instigante área de investigação.

0 artigo de Agustín Escolano, com o qual abrimos este dossiê, empreende uma análise historiográfica e teórica sobre a identidade do livro escolar, concebido como um gênero textual específico, oferecendo elementos para pensá-lo no âmbito da cultura da escola tradicional, assim como no contexto da revolução digital. Esquadrinhando as características materiais e formais que participam da configuração da identidade do livro escolar, o autor assinala os aspectos que distinguem o livro impresso do livro digital; examina as transformações sofridas pelo livro escolar e os seus impactos sobre as formas de aquisição do conhecimento na era digital, ao mesmo tempo que detecta as similitudes e as continuidades entre ambos, explicáveis quando se têm em conta as marcas deixadas nos leitores pela experiência escolar ou, em outras palavras, o habitus produzido pela escola. Suas análises permitem atentar para as dimensões pedagógicas, políticas, econômicas e culturais que intervêm na produção, seleção e usos do livro escolar, possibilitando ver no livro, simultaneamente, um "ícone geracional”, um “símbolo nacional”, fortemente implicado nas dinâmicas de transmissão de uma cultura nacional, e um "suporte curricular”. Assinalando a relevância que vem sendo atribuída, nas últimas décadas, aos manuais escolares como fonte para a compreensão da "gramática da escolarização" e dos modos de sociabilidade das crianças e jovens, no interior das instituições escolares, o artigo instiga a interrogar, ademais, sobre o nascimento do campo intelectual e acadêmico da manualística e suas contribuições para a análise da identidade do livro escolar.

Kazumi Munakata, por sua vez, examina o livro didático como mercadoria, procurando compreender os livros destinados ao público escolar no interior do 
circuito da indústria cultural, o que the permite examiná-los em uma dupla dimensão, que envolve o seu valor de uso e o seu valor de troca. Embrenhando-se nos meandros da discussão sobre a indústria cultural e a atividade editorial, o autor defronta-se com a recorrente e inquietante indagação: o que é, afinal, um bom livro? Questão cujo tratamento não é nada óbvio e não radica tão somente no exame do conteúdo do livro, ou seja, das informações que ele põe em circulação. Objeto da cultura, o livro é reinserido nas malhas do mercado e examinado como mercadoria. No questionário que resulta dos objetivos propostos pelo autor, as análises sobre o livro didático voltam-se para a interrogação sobre a sua relevância no conjunto da economia livreira, bem como sobre os vínculos entre a expansão do mercado de livros destinados à escola, a expansão da escolarização e os processos de consolidação e fortalecimento dos Estados Nacionais. Sem perder de vista as dimensões históricas da produção do livro escolar, o artigo traz importantes contribuições para a reflexão sobre as atuais políticas adotadas pelo Estado brasileiro, no que tange à avaliação dos livros escolares; e sobre as dimensões econômicas envolvidas no Programa Nacional do Livro Didático, programa esse que, como indicam os dados levantados pelo autor, movi- menta "cifras astronômicas". Chamando a atenção para os múltiplos atores que participam da produção do livro, o autor não se furta à indagação sobre os usos que professores e alunos fazem dessa mercadoria.

Apresentamos, em seguida, o artigo de Brigitte Morand, em que a autora analisa os manuais escolares como suporte de representações sociais, interrogando, mais especificamente, acerca das representações da Guerra Fria nos manuais franceses de história e geografia destinados aos estudantes do ensino secundário, produzidos entre 1959 e 2006. Afastando-se de uma análise do manual escolar como suporte de transposição didática, Morand o toma como objeto cultural complexo ou como "objeto multipolar”, em cuja produção se articulam distintas lógicas. Por meio de um exercício de análise que parte do cruzamento entre os manuais selecionados e os programas de ensino do período, seguido de um exame dos manuais em que se combinam métodos quantitativos e qualitativos, a autora procura compreender o tratamento conferido à temática da Guerra Fria, detendo-se na iconografia das obras examinadas, em suas articulações com o texto. Procedimento esse que lhe permite detectar o lugar assumido pela noção de uma "partilha do mundo" entre duas grandes 
potências, encenado na iconografia que percorre os livros do período.

Tal noção, como assinala Morand, encontra rebatimento nas imagens veiculadas pela imprensa diária, que também passam a ocupar um lugar de destaque na produção dos manuais escolares. Circunscrevendo suas análises ao cenário francês, a autora indaga sobre o papel dos manuais escolares e, de modo mais específico, dos manuais de história, na constituição de representações sobre a França e o seu lugar no mundo. Chega, por essa via, a uma instigante afirmação acerca do caráter muito mais mítico que científico das narrativas produzidas pelos manuais. As análises de Morand contribuem, de modo significativo, para a interrogação acerca das aproximações entre as lógicas que presidem a produção dos manuais escolares e o funcionamento da imprensa, possibilitando, nesse sentido, um tratamento dos manuais como "mídia de massa".

Antônio Augusto Batista, por seu turno, indaga sobre os efeitos dos livros escolares no processo de aculturação das crianças. Partindo da observação da recorrência do que denomina "a retórica da infelicidade", traduzida na presença da morte; da tristeza; da dor; do desamparo, nos livros escolares de leitura destinados às crianças das escolas elementares brasileiras e, de modo mais específico, naqueles que compõem o cânone republicano, o autor analisa os procedimentos retórico-discursivos que dão sustentação à construção dessa carga dramática e catastrófica. Suas análises incidem sobre as "narrativas escolares", modelo de leitura que apela aos sentimentos das crianças, visando promover a sua identificação com os valores postos em circulação e, por essa via, reforçar os laços sociais, interrogando sobre os efeitos de aculturação que o recurso à dor e ao sofrimento pode produzir. Examinando os "pactos de leitura", organizados, como assinala o autor, "sob o signo da proximidade emocional”; os elementos descritivos; os modos como se constrói a narrativa e como se produz um mundo ficcional em que deveriam se inserir as crianças, o artigo oferece elementos para a compreensão do trabalho sobre as emoções das crianças, que fez parte do empreendimento de constituição da escola republicana. Nos modos de construção dos textos analisados, emergem as representações de uma criança frágil, desprotegida, desamparada, sujeita a constantes ameaças, envolta em uma atmosfera tensa e dramática, cuja conduta deveria ser dirigida e guiada ou, em uma palavra, governada. Os livros escolares examinados por Batista inserem-se, nesse sentido, num projeto de formação do espírito das crianças. 
Analisando o caso espanhol, Antonio Viñao Frago propõe uma reflexão sobre os manuais escolares como parte da história das disciplinas escolares, defendendo a pertinência de pensar a constituição das disciplinas escolares em suas relações com o processo de profissionalização docente e de formação dos professores. Suas análises tomam como ponto de partida a indagação sobre os motivos da ausência de uma reflexão histórica a respeito dos processos de disciplinarização das distintas matérias escolares, atividades ou áreas disciplinares, tanto no currículo de formação dos professores espanhóis, como na produção veiculada nos principais periódicos especializados. Adverte, nesse sentido, para os impactos de tal ausência nas possibilidades de reflexão dos professores sobre a educação e a escola. Sua defesa da relevância da introdução da história das disciplinas na formação docente apoia-se em aspectos ligados ao lugar que ocupam a disciplina e o nível de ensino, no processo de profissionalização docente, na constituição da identidade profissional e na configuração das culturas escolares. É, pois, pela via da história das disciplinas escolares, que Viñao ressalta a importância da manualística, destacando a confluência entre os investimentos voltados para a análise da produção, da comercialização e dos usos dos manuais escolares e aqueles direcionados para a compreensão da história de determinadas disciplinas ou atividades. Para além de tal confluência, defende o autor que a história dos manuais somente ganha sentido histórico pleno, quando inserida no âmbito da história das disciplinas escolares, propondo, desse modo, uma inversão em relação à situação que hoje se observa, em que a investigação da história destas tem resultado dos investimentos no campo da história dos manuais escolares. Suscita, assim, uma importante reflexão sobre a agenda dos estudos no campo da manualística.

Fica o convite aos leitores da revista Pro-Posições a seguir conosco esta instigante imersão no universo dos livros destinados ao público escolar, em diferentes momentos históricos e em diferentes países, bem como no universo das investigações no campo da manualística e suas promissoras contribuições para a compreensão da cultura escolar. 
